\title{
Mechanical Properties and Failure Topography of Banana Fiber PF Macrocomposites Fabricated by RTM and CM Techniques
}

\author{
K. N. Indira, ${ }^{1}$ Jyotishkumar Parameswaranpillai, ${ }^{2}$ and Sabu Thomas ${ }^{3,4,5}$ \\ ${ }^{1}$ Department of Chemistry, T.K.M.M. College, Nangiarkulangara, Kerala 690513, India \\ ${ }^{2}$ Department of Polymer Science and Rubber Technology, Cochin University of Science and Technology, Cochin, \\ Kerala 682 022, India \\ ${ }^{3}$ School of Chemical Sciences, Mahatma Gandhi University, Priyadarshini Hills, Kottayam, Kerala 686560, India \\ ${ }^{4}$ Faculty of Applied Sciences, Universiti Teknologi MARA, 40450 Shah Alam, Selangor, Malaysia \\ ${ }^{5}$ Center of Excellence for Polymer Materials and Technologies, Tehnoloski park 24, 1000 Ljubljana, Slovenia
}

Correspondence should be addressed to Jyotishkumar Parameswaranpillai; jyotishkumarp@gmail.com

Received 23 June 2013; Accepted 17 July 2013

Academic Editors: C. Bernal and J. I. Velasco

Copyright (C) 2013 K. N. Indira et al. This is an open access article distributed under the Creative Commons Attribution License, which permits unrestricted use, distribution, and reproduction in any medium, provided the original work is properly cited.

\begin{abstract}
Banana fiber reinforced phenol formaldehyde composites with different fiber lengths and fiber loadings were prepared by compression molding (CM) and resin transfer molding (RTM) techniques. The mechanical properties such as tensile, flexural, and impact behavior were studied. RTM composites showed improved tensile and flexural properties as compared to CM composites. On the other hand, impact strength of RTM composites is slightly lower than that of CM composites. From the studies, it was found that mechanical properties increased with the increase in fiber loading, reached a plateau at 30-40 wt $\%$, and then subsequently decreased with an increase in fiber loading in both techniques. At high fiber weight fractions, the strength decreased due to poor wetting and very poor stress transfer. The stress value increased up to $30 \mathrm{~mm}$ fiber lengths and then decreased. In order to examine the fracture surface morphology of the composites, scanning electron microscopy (SEM) was performed on the composite samples. A good relationship between morphological and mechanical properties has been observed. Finally, tensile strength of the composites fabricated by RTM and CM was compared with theoretical predictions.
\end{abstract}

\section{Introduction}

In recent years, there has been a tremendous interest in the usage of plant fibers as reinforcement in polymer matrices for the manufacture of automobile components [1-6]. Lignocellulosic materials can significantly contribute to the development of biobased composites [7-9]. A few reports from the literature on green fiber polymer composites are summarized afterwords. Francucci et al. worked to understand how the main processing variables are affected when glass fibers are replaced by natural fibers in reinforced plastics [10]. Good flow properties and appreciable mechanical properties came to attention when Oksman manufactured high quality flax fiber reinforced composite using RTM [11]. Sreekumar et al. studied the mechanical and water absorption properties of sisal fiber reinforced polyester composites fabricated by RTM and CM techniques. They found that the composites made by RTM exhibited superior mechanical property and less water sorption due to good fiber/matrix interaction which was a result of low void content and good fiber wetting [12]. Peponi et al. extended a statistical approach to develop a comparative study on the mechanical properties of different natural fibers [13]. Kaith and Kalia studied grafting of flax fiber with vinyl monomers for enhancement of properties of flax-phenolic composites [14]. Megiatto et al. studied the effects of the polymeric coating layer as a coupling agent in phenolic/sisal fibers composites. Since the fibers were partially degraded by the chemical treatment, the impact strength of the sisal-reinforced composites was decreased [15]. A new biodegradable composite of hemp 
TABle 1: Properties of banana fiber.

\begin{tabular}{|c|c|c|c|c|c|c|c|c|}
\hline $\begin{array}{l}\text { Tensile } \\
\text { strength } \\
(\mathrm{MPa})\end{array}$ & $\begin{array}{c}\text { Tensile } \\
\text { modulus } \\
(\mathrm{GPa})\end{array}$ & $\begin{array}{c}\text { Elongation } \\
\text { at break } \\
(\%)\end{array}$ & $\begin{array}{l}\text { Diameter } \\
\text { of the fiber } \\
\text { (microns) }\end{array}$ & $\begin{array}{l}\text { Density } \\
\left(\mathrm{g} / \mathrm{cm}^{3}\right)\end{array}$ & $\begin{array}{c}\text { Cellulose } \\
\text { content } \\
(\%)\end{array}$ & $\begin{array}{c}\text { Hemicellulose } \\
(\%)\end{array}$ & Lignin (\%) & Moisture (\%) \\
\hline $540 \pm 9$ & $29 \pm 2$ & $3 \pm 0.2$ & $80 \pm 2$ & $1.3 \pm 0$ & $63 \pm 1$ & $19 \pm 1.2$ & $5 \pm 0.5$ & $11 \pm 0.1$ \\
\hline
\end{tabular}

fiber reinforced polylactic acid was fabricated by $\mathrm{Hu}$ and Lim using the hot press method. Mechanical properties of composites with different fiber volume fractions were tested, and the effects of alkali treatment on the fiber surface morphology and the mechanical properties of the composites were investigated. Test results show that the composite with $40 \mathrm{wt} \%$ volume fraction of alkali-treated fiber has the best mechanical properties [16]. Abdelmouleh et al. prepared composite materials based on cellulose fibers (raw or chemically modified) as reinforcing elements and thermoplastic as matrices, and the composites were characterized in terms of their mechanical performances [17]. Alawar et al. worked on the characterization of treated date palm tree fiber as composite reinforcement [18]. From the literature, it can be seen that different plant fibers have been used for the development of biobased composites for a wide range of applications including housing and automotive panels and furniture.

In our previous studies, we have examined the effectiveness of various natural fibers like banana, oil palm empty fruit bunch, sisal fiber, and so forth as potential reinforcing agents in various polymeric matrices [19-24]. The present paper highlights a thorough investigation of the mechanical properties such as tensile, flexural, and impact strength of banana fiber reinforced PF composites prepared by RTM and CM techniques. The studies were done by varying fiber length and fiber loading. The mechanical properties of the composites show a great improvement and were found to be dependent on the fiber length and fiber loading. Scanning electron microscopy (SEM) studies have been carried out to get an insight into fiber/matrix interaction and fiber breakage. Attempt has been made to compare the mechanical properties of the composites fabricated by CM and RTM techniques with theoretical predictions.

\section{Experimental}

2.1. Materials. The reinforcement, banana fiber used in the present study was obtained from Sheeba fibers and handicrafts, Poovancode, Tamilnadu, India. Phenol formaldehyde resole type resin obtained from M/S West Coast Polymers Pvt. Ltd., Kannur, Kerala, India, was used as matrix. Phenol formaldehyde resin has a dark brown colour, with a viscosity of 18CPS and a density of $1.3 \mathrm{~g} / \mathrm{cm}^{3}$. Sodium hydroxide (commercial grade), acetic acid (commercial grade), sodium hypochlorite (commercial grade), and oxalic acid (commercial grade) were obtained from Nice Chemicals, Cochin, India. Important characteristics of banana fiber are given in Table 1 .

\subsection{Fabrication of Phenol Formaldehyde Composites}

2.2.1. Macrocomposites. Banana fibers were chopped to the desired length, dried in an air oven at $70^{\circ} \mathrm{C}$ for $4 \mathrm{hrs}$, and then dried in a vacuum oven at $60^{\circ} \mathrm{C}$ for $1 \mathrm{~h}$ before the preparation of composites. The mould was polished, and mould releasing agent was applied. The cleaned fibers were arranged in the mould in the form of mats and pressed. Composites were fabricated using compression moulding (CM) and resin transfer moulding (RTM) methods. The dimensions of the mould in CM technique was $150 \times 150 \times 3 \mathrm{~mm}^{3}$, and that of RTM was $300 \times 200 \times 3 \mathrm{~mm}^{3}$. The composite samples were prepared by prepreg method in CM. Here, the resin was poured into the mat until it was completely soaked. The mould was closed and hot pressed at a temperature of $130^{\circ} \mathrm{C}$ for $20 \mathrm{~min}$ at a pressure of $10 \mathrm{~kg} / \mathrm{cm}^{2}$, and the curing was done. In RTM, phenol formaldehyde was injected into the dry banana fiber, which was placed in the mould cavity. An optimum pressure of $1 \mathrm{~kg} / \mathrm{cm}^{2}$ was maintained. Simultaneously, vacuum was applied. The resin spreads through the mould and impregnates the fiber by pushing the air, if any, left in the mould. Thus, the resulting composite has low void content and better interfacial adhesion. All the samples prepared were subjected to postcuring operation at $70^{\circ} \mathrm{C}$ for $1 \mathrm{~h}$ to ensure complete curing. Composite samples were prepared by CM and RTM techniques by varying fiber length $(10,20,30$, and $40 \mathrm{~mm})$ and fiber loading $(10,20,30,40$, and $50 \mathrm{wt} \%)$.

\subsection{Characterisation}

2.3.1. Scanning Electron Microscopy (SEM) Analysis. Scanning electron micrographs of composites were captured using Philips SEM 515. The samples were coated with platinum using sputtering technique.

2.3.2. Mechanical Testing. Tensile testing was carried out using FIE electronic universal testing machine TNE 500 according to ASTM D638-76. Three point flexure properties were also tested using the same machine according to ASTM D790. Charpy impact strength (unnotched) was measured in a WinPEN CEAST S.p.A., Italy, according to ISO 179.

\section{Results and Discussion}

\subsection{Tensile Behavior of Phenol Formaldehyde/Banana Fiber Composites}

3.1.1. Effect of Fiber Length. The properties of the composite are strongly influenced by the fiber length. The fiber length 


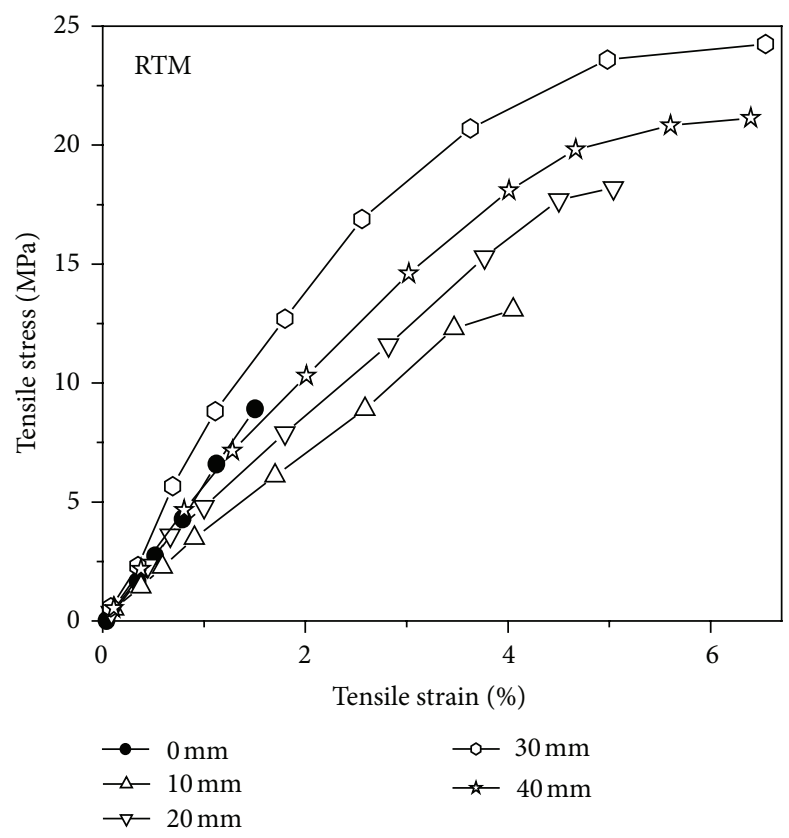

(a)

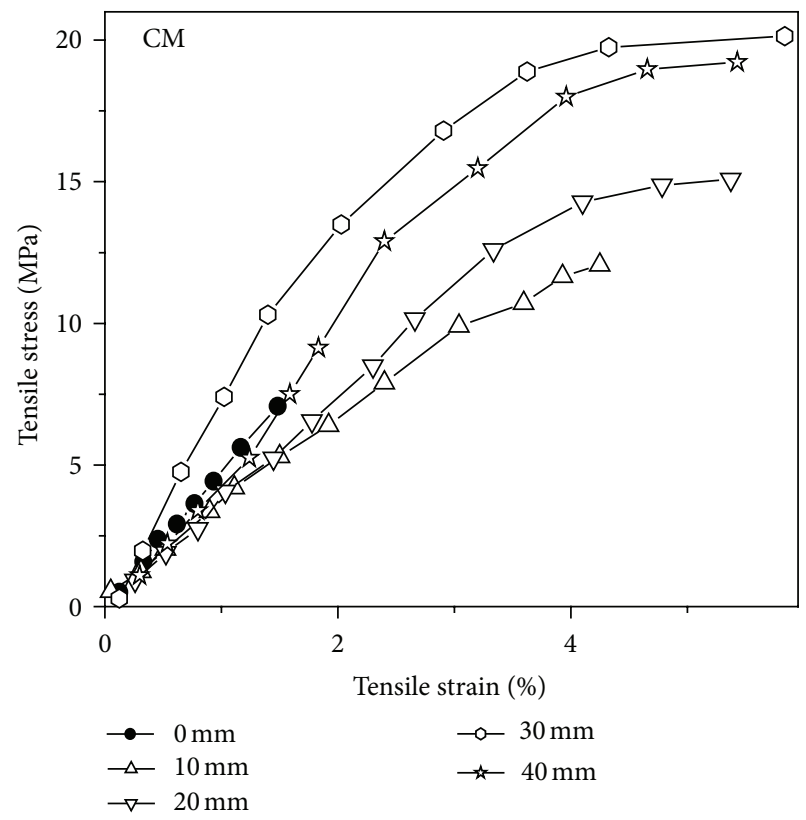

(b)

FIGURE 1: Tensile stress-strain behavior of banana fiber/PF composites fabricated by (a) RTM and (b) CM techniques at different fiber lengths (fiber loading $30 \mathrm{wt} \%$ ).

TABLE 2: Tensile properties of banana fiber/phenol formaldehyde composites at different fiber lengths (fiber content $30 \mathrm{wt} \%$ ).

\begin{tabular}{lcccc}
\hline \multirow{2}{*}{ Fiber length $(\mathrm{mm})$} & \multicolumn{2}{c}{ RTM } & \multicolumn{2}{c}{ CM } \\
& Tensile strength $(\mathrm{MPa})$ & Elongation at break (\%) & Tensile strength (MPa) & Elongation at break (\%) \\
\hline 0 & $9 \pm 1.0$ & 1.49 & $7 \pm 2.0$ & 1.47 \\
10 & $13 \pm 1.3$ & 4.0 & $12 \pm 1.5$ & 4.2 \\
20 & $18 \pm 1.5$ & 5.0 & $15 \pm 1.2$ & 5.3 \\
30 & $24 \pm 2.1$ & 6.5 & $20 \pm 2.4$ & 5.8 \\
40 & $21 \pm 1.8$ & 6.4 & $19 \pm 0.9$ & 5.4 \\
\hline
\end{tabular}

plays an important role in the fracture of short fiber composites. To gain maximum level of stress in the fiber, the fiber length must be at least equal to the critical fiber length [19]. Figures 1(a) and 1(b) show the stress-strain behavior of the composites fabricated by RTM and CM techniques, respectively, at different fiber lengths. The tensile strength or maximum stress at break expresses the load the material can bear before it ruptures. The stress-strain curve of PF explains the brittle fracture nature. The plasticizing effect increases in fiber-filled composites due to the presence of cellulosic fiber. Composites with $10 \mathrm{~mm}$ and $20 \mathrm{~mm}$ fiber length have high plastic deformation due to less fiber entanglement. At high fiber lengths (30 and $40 \mathrm{~mm}$ ), a stable network structure can occur throughout the composite, which hinders easy deformation within the composite upon application of an external stress. The composites show a linear behavior at low strains followed by a significant change in slope showing a nonlinear behavior which is maintained up to the complete failure of the composite. RTM and CM composites show a similar trend evidenced by the similar stress-strain behavior. The tensile strengths for PF/banana fiber composites fabricated by RTM and $\mathrm{CM}$ techniques as a function of fiber length are given in Table 2. Tensile strength gets increased with fiber length, and the maximum value is for $30 \mathrm{~mm}$ fiber and thereafter decreased. Therefore, for PF/banana composites, the fiber length $30 \mathrm{~mm}$ is optimized in both techniques. In the case of fibers shorter than this optimum length (lower than critical fiber length), the fibers will debone from the matrix resulting in failure of composite under low strain. Similarly, lowering of stress value at higher fiber length (greater than critical fiber length) was observed, because the effective stress transfer is not possible due to fiber curling and fiber bending. The processing method does not affect the optimum fiber length since it depends on length and diameter of fiber. Sreekumar [12] and Joseph [19] et al. reported a similar trend in the case of polyester/sisal and PF/banana fiber composites that the maximum mechanical properties were for the composite having critical fiber length. Thus, it can be concluded that the fiber-having length of $30 \mathrm{~mm}$ was found to be the optimum for effective reinforcement in PF. It is important to mention that the tensile strengths of the RTM composites were higher than CM composites. The better properties in RTM-moulded 
TABLE 3: Tensile properties of banana fiber/phenol formaldehyde composites at different fiber loadings (fiber length $30 \mathrm{~mm}$ ).

\begin{tabular}{lcccc}
\hline \multirow{2}{*}{ Fiber loading (wt\%) } & \multicolumn{2}{c}{ RTM } & \multicolumn{2}{c}{ CM } \\
& Tensile strength (MPa) & Elongation at break (\%) & Tensile strength (MPa) & Elongation at break (\%) \\
\hline 0 & $9 \pm 1.0$ & 1.49 & $7 \pm 2.0$ & 1.47 \\
10 & $14 \pm 2.4$ & 4.3 & $13 \pm 1.6$ & 4.5 \\
20 & $19 \pm 1.6$ & 5.2 & $16 \pm 2.7$ & 5.0 \\
30 & $24 \pm 2.1$ & 6.5 & $20 \pm 2.4$ & 5.8 \\
40 & $28 \pm 1.9$ & 6.6 & $24 \pm 1.9$ & 6.0 \\
50 & $26 \pm 1.2$ & 7.0 & $21 \pm 1.7$ & 6.5 \\
\hline
\end{tabular}

TABLE 4: Flexural strength of banana fiber/phenol formaldehyde composites at different fiber lengths (fiber content $30 \mathrm{wt} \%$ ).

\begin{tabular}{lcc}
\hline Fiber length $(\mathrm{mm})$ & $\begin{array}{c}\text { RTM } \\
\text { Flexural strength } \\
(\mathrm{MPa})\end{array}$ & $\begin{array}{c}\text { CM } \\
\text { Flexural strength } \\
(\mathrm{MPa})\end{array}$ \\
\hline 0 & $11 \pm 1.8$ & $10 \pm 2.0$ \\
10 & $28 \pm 2.1$ & $25 \pm 1.7$ \\
20 & $36 \pm 1.4$ & $33 \pm 2.4$ \\
30 & $44 \pm 2.6$ & $41 \pm 1.8$ \\
40 & $40 \pm 1.3$ & $38 \pm 2.0$ \\
\hline
\end{tabular}

composites were due to lesser voids which led to better fibermatrix interaction [12].

3.1.2. Effect of Fiber Content. Table 3 describes tensile strength for PF/banana fiber composites fabricated by RTM and CM techniques as a function of fiber loading. The tensile strength increased with the increase in fiber loading up to $40 \mathrm{wt} \%$ and then decreased in both techniques, and a maximum property was obtained at $40 \mathrm{wt} \%$ loading. Addition of fiber makes the PF matrix ductile. At lower fiber loading (10$30 \mathrm{wt} \%)$, dispersion of fiber is so poor that the stress transfer will not occur properly. At higher fiber loading (50 wt\%), there is a strong tendency for fiber-fiber interaction. This leads to poor wetting of fibers and fiber dispersion. In such a case, crack initiation and its propagation will be easier [25]. Even if fiber/matrix bonding is present, poorly dispersed fibers give rise to fiber-fiber interactions and reduce the load-bearing capability of the fibers and thereby reduce the available stress transfer area.

3.2. Flexural Behavior as a Function of Fiber Length and Fiber Content. By the application of flexural force, the upper and lower surfaces of the specimen under three point bending load are subjected to compression and tension, and the axisymmetric plane is subjected to shear stress. This creates two failure modes in the material: bending and shear failure. The specimen fails when bending or shear stress reaches the corresponding critical value. The modes of failure of the composites under three point bending can be obtained from the force deflection curves. The deformation behavior of $\mathrm{PF} /$ banana fiber composites fabricated by RTM and CM techniques as a function of fiber length and fiber content under flexural stress is given in Tables 4 and 5, respectively. From
TABLE 5: Flexural strength of banana fiber/phenol formaldehyde composites at different fiber loadings (fiber length $30 \mathrm{~mm}$ ).

\begin{tabular}{lcc}
\hline Fiber loading (wt\%) & $\begin{array}{c}\text { RTM } \\
\text { Flexural strength } \\
(\mathrm{MPa})\end{array}$ & $\begin{array}{c}\text { CM } \\
\text { Flexural strength } \\
(\mathrm{MPa})\end{array}$ \\
\hline 0 & $11 \pm 1.8$ & $10 \pm 2.0$ \\
10 & $27 \pm 2.8$ & $25 \pm 1.9$ \\
20 & $37 \pm 3.4$ & $34 \pm 2.3$ \\
30 & $44 \pm 2.6$ & $41 \pm 1.8$ \\
40 & $48 \pm 1.8$ & $44 \pm 2.9$ \\
50 & $43 \pm 2.6$ & $39 \pm 3.0$ \\
\hline
\end{tabular}

the tables, the flexural strength increases with increasing fiber length and fiber loading. Maximum value is found for $30 \mathrm{~mm}$ long fiber composites with $40 \mathrm{wt} \%$ fiber content. Xue et al. [26] also observed an increase in the mechanical properties of kenaf fiber composites with increasing fibre content. In the case of flexural properties too, a definite distinction can be seen for different processing techniques via RTM and CM; the former resulted in better properties. This is due to the less fiber/fiber contact, that is, good wettability and less void content in RTM.

3.3. Izod Impact Behavior as a Function of Fiber Length and Fiber Loading. Impact resistance of a composite is a measure of the total energy dissipated in the material before final failure occurs. Figures 2(a) and 2(b) display the Izod impact strength of the PF/banana fiber composites fabricated by RTM and CM techniques as a function of fiber length and fiber content, respectively. As the cellulose fibres are more porous, the impact strength of the composites increases with the increase in fibre loading. In both techniques, the impact strength was found to increase up to $30 \mathrm{~mm}$ fiber length and then decrease with the increasing fiber length. As the length of fiber increases, the number of fiber ends and number of defects will be low [27]. However, after an optimum fiber length, the effective stress transfer is not possible due to fiber curling and fiber bending. So, a small decrease in impact strength is noticed as the fiber length increases [28]. The impact strength increased with increase in fiber loading up to $40 \mathrm{wt} \%$ and then decreased in both techniques, and a maximum property was obtained at $40 \mathrm{wt} \%$ loading. The impact strength of RTM composite is slightly lower than CM composite at all fiber loadings [8]. It indicates 


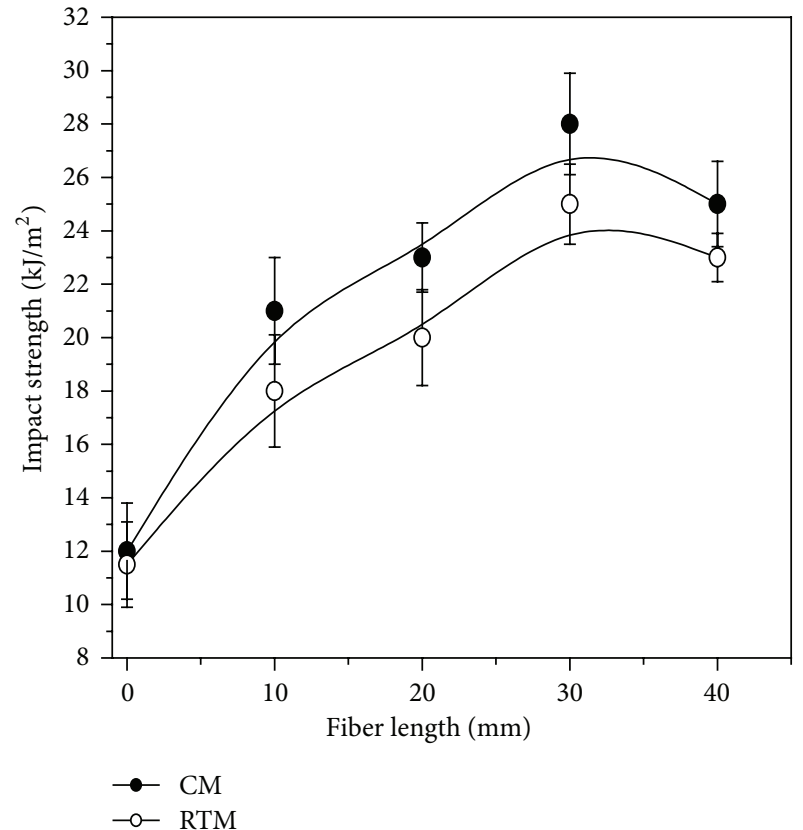

(a)

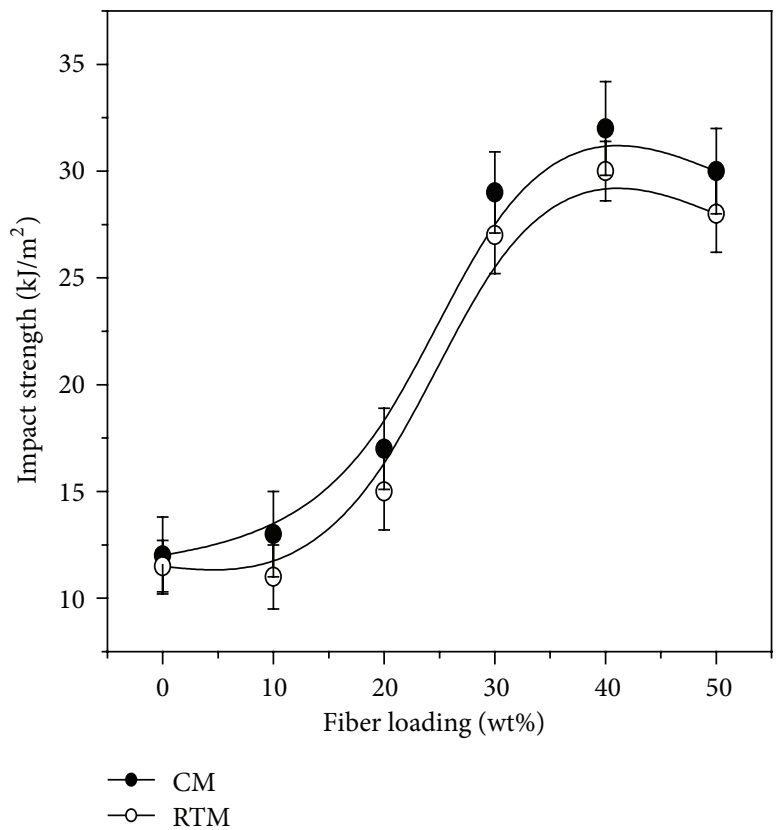

(b)

Figure 2: Impact properties of banana fiber/PF composites at (a) different fiber lengths (fiber loading 30 wt\%), (b) different fiber loadings (fiber length $30 \mathrm{~mm}$ ).

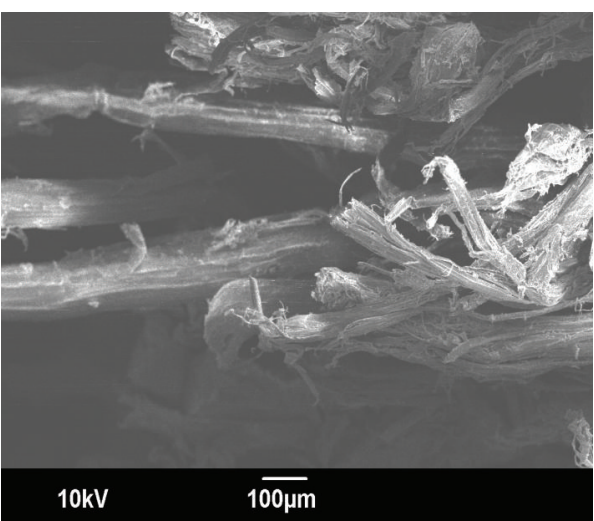

(a)

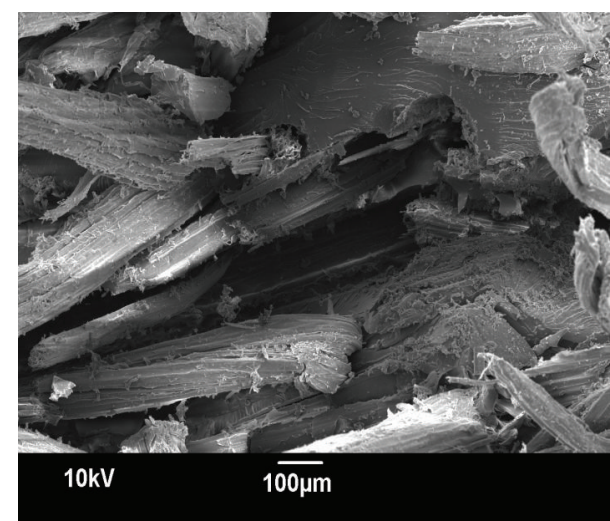

(b)

FIGURE 3: SEM impact fractograph of $30 \mathrm{~mm}$ banana fiber/PF composite with $40 \mathrm{wt} \%$ fiber loading fabricated by (a) RTM and (b) CM techniques.

the increased fiber/matrix interaction in RTM composites more than the CM composites. The impact strength of a composite depends upon many factors like toughness properties of the reinforcement, the nature of the interfacial region, and frictional work involved in pulling out of the fiber from the matrix. If the interfacial bonding of the composite is weak as in the case of CM composites, the crack will be propagated along the fiber matrix/interface causing debonding. As a result of debonding, new surfaces will be produced which lead to a significant increase in the energy absorbing capacity of the composites [29]. Therefore, it can be expected that the impact strength of the CM composites would be higher when compared to RTM composites. This can be explained by the SEM micrographs.

Figures 3(a) and 3(b) show the impact fracture surfaces of $30 \mathrm{~mm}$ banana fibre/PF composites with $40 \mathrm{wt} \%$ fiber content fabricated by RTM and CM, respectively. More fibre crowding is seen in CM composite. Fibre pullout is easier in this case. Clean fibre pullout in CM composite explains the decreased fibre/matrix interaction compared with RTM composites. The extent of fibre pullout is lower for RTM composite. From our studies, we can conclude that the optimum condition for improved mechanical strength is with $30 \mathrm{~mm}$ long fiber composites with $40 \mathrm{wt} \%$ fiber content. 


\section{Theoretical Modeling}

4.1. Modeling of Mechanical Properties. Theoretical values of tensile strength of short banana fiber reinforced PF resin composites have been determined by making use of various models like modified rule of mixtures (ROM), parallel, series, and Hirsch models. They have subsequently been compared with the experimental values.

4.1.1. Rule of Mixtures. The rule of mixtures is the most popular method used to calculate the strength of the fiber reinforced composite. The tensile strength $T_{c}$ is given by the following equations.

Parallel model:

$$
T_{c}=T_{f} V_{f}+T_{m} V_{m}
$$

Series model:

$$
T_{c}=\frac{T_{m} T_{f}}{T_{m} V_{f}+V_{m} T_{f}} .
$$

Modified rule of mixtures (ROM):

$$
T_{c}=\eta T_{f} V_{f}+\left(1-V_{f}\right) T_{m},
$$

where $T_{c}, T_{m}$, and $T_{f}$ are the tensile strengths of the composite, matrix, and fiber, respectively. $V_{m}$ and $V_{f}$ are the volume fractions of matrix and fiber, respectively. $\eta$ is the additional coefficient which accounts for the weakening of the composite due to fiber orientation and is less than 1.

4.1.2. Hirsch's Model. Hirsch's model is a combination of parallel and series models [30]. According to this model, tensile strength is calculated using the following equation:

$$
T_{c}=x\left(T_{m} V_{m}+T_{f} V_{f}\right)+\frac{(1-x) T_{m} T_{f}}{\left(T_{m} T_{f}+T_{f} V_{m}\right)} .
$$

The value of $x$ varies between 0 and 1 , which is a good indication of effective stress transfer in the composites [31].

Variation of experimental and theoretical tensile strength values of banana fiber/PF composites fabricated by RTM and $\mathrm{CM}$ techniques as a function of fiber loading is displayed in Figure 4. The experimental results illustrate that there is an increase in strength with the increase in fiberloading up to $40 \mathrm{wt} \%$ volume fraction and then a subsequent decline. Modified ROM prediction is in some agreement with the experimental data. The agreement was viable only when the value of $\eta$ is 0.1 . The modified ROM accounts for the uniform fiber dispersion within the matrix, which enables it to predict the strength. Series model gives lower values than experimental values. The deviations arise because the interaction between the components is not taken into consideration in the series model. According to this model, the fiber and matrix exist as two components without any adhesion, but in actual composite systems, there is a chance of interaction between the components depending on the chemical nature of the constituents. Parallel modeling is

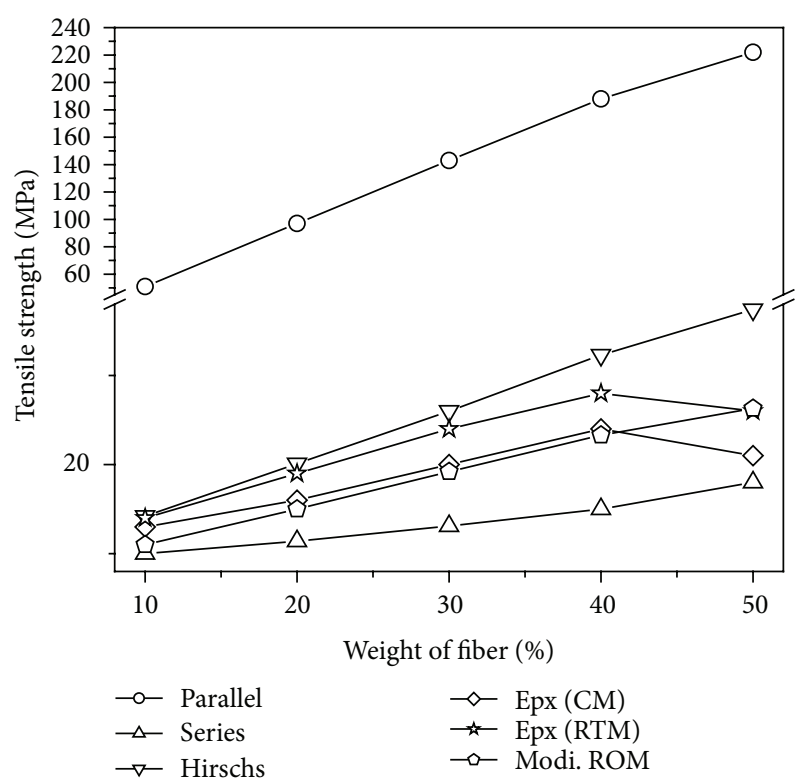

FIgURE 4: Experimental and theoretical values of tensile strength for $30 \mathrm{~mm}$ banana fiber/PF composites at $25^{\circ} \mathrm{C}$ fabricated by RTM and CM.

found to be irreconcilable to any models or experimental values, whereas Hirsch's reveals slightly higher values. The most fitting value of $x$ in this model is 0.1 , and the value of $x$ in this model is found to be a decisive factor for elaborating the behavior of short fiber composites [12]. The deviation of the predicted values from the experimental results at higher fiber loading for Hirsch's models can be attributed to the structural defects that occurred during processing. At higher fiber loading, processing becomes difficult, and fiber agglomeration or phase separation may occur during processing. Hence, the applied load was seen distributed unevenly between nonagglomerated and agglomerated fibers. Consequently, experimental values were seen to deviate from Hirsch's model at higher fiber loading. What was observed from the deviation for the CM samples from Hirsch's modeling was that the fiber/matrix adhesion is not very good. It is also noted that agglomeration and void content are very high when compared to RTM composites. This increases the fiber-to-fiber contact, which results in decreased fiber/matrix adhesion and decreased strength properties.

\section{Conclusion}

The mechanical properties of banana fiber/PF resin composites fabricated by RTM and CM techniques were analyzed as a function of fiber length and fiber loading. Tensile and flexural properties were found to be higher in RTM composites as compared to CM composites at all values of fiber loading. At higher fiber lengths, the stress value was lowered due the entanglements and fiber curling. The optimized fiber length was $30 \mathrm{~mm}$. It was found that increasing the fiber content had a positive effect on the tensile and flexural strengths. The tensile and flexural properties increased with fiber loading 
up to $40 \mathrm{wt} \%$ for both RTM and CM techniques and then decreased with an increase in fiber loading. The impact strength of RTM composites is slightly lower than that of CM composites. SEM indicated that the extent of fiber pullout was lower for RTM composites in comparison with CM composites. Thus, fiber/matrix interaction is substantially improved in RTM composites. Therefore, it can be concluded that the mechanical properties of the composites are intimately dependent on the fabrication techniques.

\section{Acknowledgments}

The authors acknowledge the financial support from (1) The Ministry of Higher Education, Science and Technology of the Republic of Slovenia through the contract no. 3211-10-000057 (Center of Excellence Polymer Materials and Technologies). (2) Nanomission, DST, India. (3) Dr. P. Jyotishkumar acknowledges the Department of Science and Technology, Government of India, for financial support under INSPIRE Faculty Fellowship [IFA-CH-16].

\section{References}

[1] F. T. Wallenberger, "Value-in-use of composite reinforcing fibers," MRS Proceedings, vol. 702, 2001.

[2] D. Plackett, "The natural fiber-polymer composite industry in Europe technology and markets," in Proceedings of the Progress on Woodfibre-Plastic Composites Conference, University of Toronto and Materials and Manufacturing Ontario, Toronto, Canada, 2002.

[3] B. C. Suddell and W. J. Evans, "The increasing use and application of natural fibre composites materials within the automotive industry," in Proceedings of the 7th International Conference on Woodfiber-Plastic Composites, Forest Products Society, Madison, Wis, USA, 2003.

[4] J. Müssig, M. Karus, and R. R. Franck, "Bast and leaf fibre composite materials," in Bast and Other Plant Fibres, R. R. Franck, Ed., vol. 345, chapter 10, Woodhead Publishing Limited, Cambridge, UK, 2005.

[5] A. K. Bledzki, V. E. Sperber, and O. Faruk, "Natural and wood fiber reinforcement in polymers," Rapra Review Reports, vol. 13, p. 152, 2002.

[6] C. M. Clemons and D. F. Caulfield, "Functional fillers for plastics," in Natural Fibers, M. Xanthos, Ed., vol. 249, chapter 11, Wiley-VCH, Weinheim, Germany, 2005.

[7] K. G. Satyanarayana, K. Sukumaran, P. S. Mukherjee, C. Pavithran, and S. G. K. Pillai, "Natural fibre-polymer composites," Cement and Concrete Composites, vol. 12, no. 2, pp. 117-136, 1990.

[8] K. G. Satyanarayana, G. G. C. Arizaga, and F. Wypych, "Biodegradable composites based on lignocellulosic fibers: an overview," Progress in Polymer Science, vol. 34, no. 9, pp. 9821021, 2009.

[9] M. J. John and S. Thomas, "Biofibres and biocomposites," Carbohydrate Polymers, vol. 71, no. 3, pp. 343-364, 2008.

[10] G. Francucci, E. S. Rodríguez, and A. Vázquez, "Study of saturated and unsaturated permeability in natural fiber fabrics," Composites A, vol. 41, no. 1, pp. 16-21, 2010.
[11] K. Oksman, "High quality flax fibre composites manufactured by the resin transfer moulding process," Journal of Reinforced Plastics and Composites, vol. 20, no. 7, pp. 621-627, 2001.

[12] P. A. Sreekumar, K. Joseph, G. Unnikrishnan, and S. Thomas, "A comparative study on mechanical properties of sisal-leaf fibre-reinforced polyester composites prepared by resin transfer and compression moulding techniques," Composites Science and Technology, vol. 67, no. 3-4, pp. 453-461, 2007.

[13] L. Peponi, J. Biagiotti, J. M. Kenny, and I. Mondragòn, "Statistical analysis of the mechanical properties of natural fibers and their composite materials. II. Composite materials," Polymer Composites, vol. 29, no. 3, pp. 321-325, 2008.

[14] B. S. Kaith and S. Kalia, "Grafting of flax fiber (Linum usitatissimum) with vinyl monomers for enhancement of properties of flax-phenolic composites," Polymer Journal, vol. 39, no. 12, pp. 1319-1327, 2007.

[15] J. D. Megiatto Jr., F. B. Oliveira, D. S. Rosa, C. Gardrat, A. Castellan, and E. Frollini, "Renewable resources as reinforcement of polymeric matrices: composites based on phenolic thermosets and chemically modified sisal fibers," Macromolecular Bioscience, vol. 7, no. 9-10, pp. 1121-1131, 2007.

[16] R. Hu and J. K. Lim, "Fabrication and mechanical properties of completely biodegradable hemp fiber reinforced polylactic acid composites," Journal of Composite Materials, vol. 41, no. 13, pp. $1655-1669$.

[17] M. Abdelmouleh, S. Boufi, M. N. Belgacem, and A. Dufresne, "Short natural-fibre reinforced polyethylene and natural rubber composites: effect of silane coupling agents and fibres loading," Composites Science and Technology, vol. 67, no. 7-8, pp. 1627$1639,2007$.

[18] A. Alawar, A. M. Hamed, and K. Al-Kaabi, "Characterization of treated date palm tree fiber as composite reinforcement," Composites B, vol. 40, no. 7, pp. 601-606, 2009.

[19] S. Joseph, M. S. Sreekala, Z. Oommen, P. Koshy, and S. Thomas, "A comparison of the mechanical properties of phenol formaldehyde composites reinforced with banana fibres and glass fibres," Composites Science and Technology, vol. 62, no. 14, pp. 1857-1868, 2002.

[20] L. A. Pothan, S. Thomas, and N. R. Neelakantan, "Short banana fiber reinforced polyester composites: mechanical, failure and aging characteristics," Journal of Reinforced Plastics and Composites, vol. 16, no. 8, pp. 744-765, 1997.

[21] G. Kalaprasad, B. Francis, S. Thomas et al., "Effect of fibre length and chemical modifications on the tensile properties of intimately mixed short sisal/glass hybrid fibre reinforced low density polyethylene composites," Polymer International, vol. 53, no. 11, pp. 1624-1638, 2004.

[22] G. Kalaprasad, G. Mathew, C. Pavithran, and S. Thomas, "Melt rheological behavior of intimately mixed short sisal-glass hybrid fiber-reinforced low-density polyethylene composites. I. Untreated fibers," Journal of Applied Polymer Science, vol. 89, no. 2, pp. 432-442, 2003.

[23] M. S. Sreekala, M. G. Kumaran, S. Joseph, M. Jacob, and S. Thomas, "Oil palm fibre reinforced phenol formaldehyde composites: influence of fibre surface modifications on the mechanical performance," Applied Composite Materials, vol. 7, no. 5-6, pp. 295-329, 2000.

[24] M. Idicula, S. K. Malhotra, K. Joseph, and S. Thomas, "Effect of layering pattern on dynamic mechanical properties of randomly oriented short banana/sisal hybrid fiber-reinforced polyester composites," Journal of Applied Polymer Science, vol. 97, no. 5, pp. 2168-2174, 2005. 
[25] R. David, S. Mohini, and M. Couturier, "Resin transfer molding of hemp fiber composites: optimization of the process and mechanical properties of the materials," Composites Science and Technology, vol. 66, no. 7-8, pp. 895-906, 2006.

[26] Y. Xue, Y. Du, S. Elder, K. Wang, and J. Zhang, “Temperature and loading rate effects on tensile properties of kenaf bast fiber bundles and composites," Composites B, vol. 40, no. 3, pp. 189196, 2009.

[27] H. G. Elias, Macromolecules, vol. 2, Plenum Press, New York, NY, USA, 2nd edition, 1984.

[28] M. K. Kang, W. I. Lee, and H. T. Hahn, "Formation of microvoids during resin-transfer molding process," Composites Science and Technology, vol. 60, no. 12-13, pp. 2427-2434, 2000.

[29] S. A. Paul, K. Joseph, G. D. G. Mathew, L. A. Pothen, and S. Thomas, "Influence of polarity parameters on the mechanical properties of composites from polypropylene fiber and short banana fiber," Composites A, vol. 41, no. 10, pp. 1380-1387, 2010.

[30] T. J. Hirsch, "Modulus of elasticity of concrete affected by elastic moduli of cement paste matrix and aggregate," Journal of the American Concrete Institute, vol. 59, p. 427, 1962.

[31] G. Kalaprasad, K. Joseph, S. Thomas, and C. Pavithran, “Theoretical modelling of tensile properties of short sisal fibrereinforced low-density polyethylene composites," Journal of Materials Science, vol. 32, no. 16, pp. 4261-4267, 1997. 

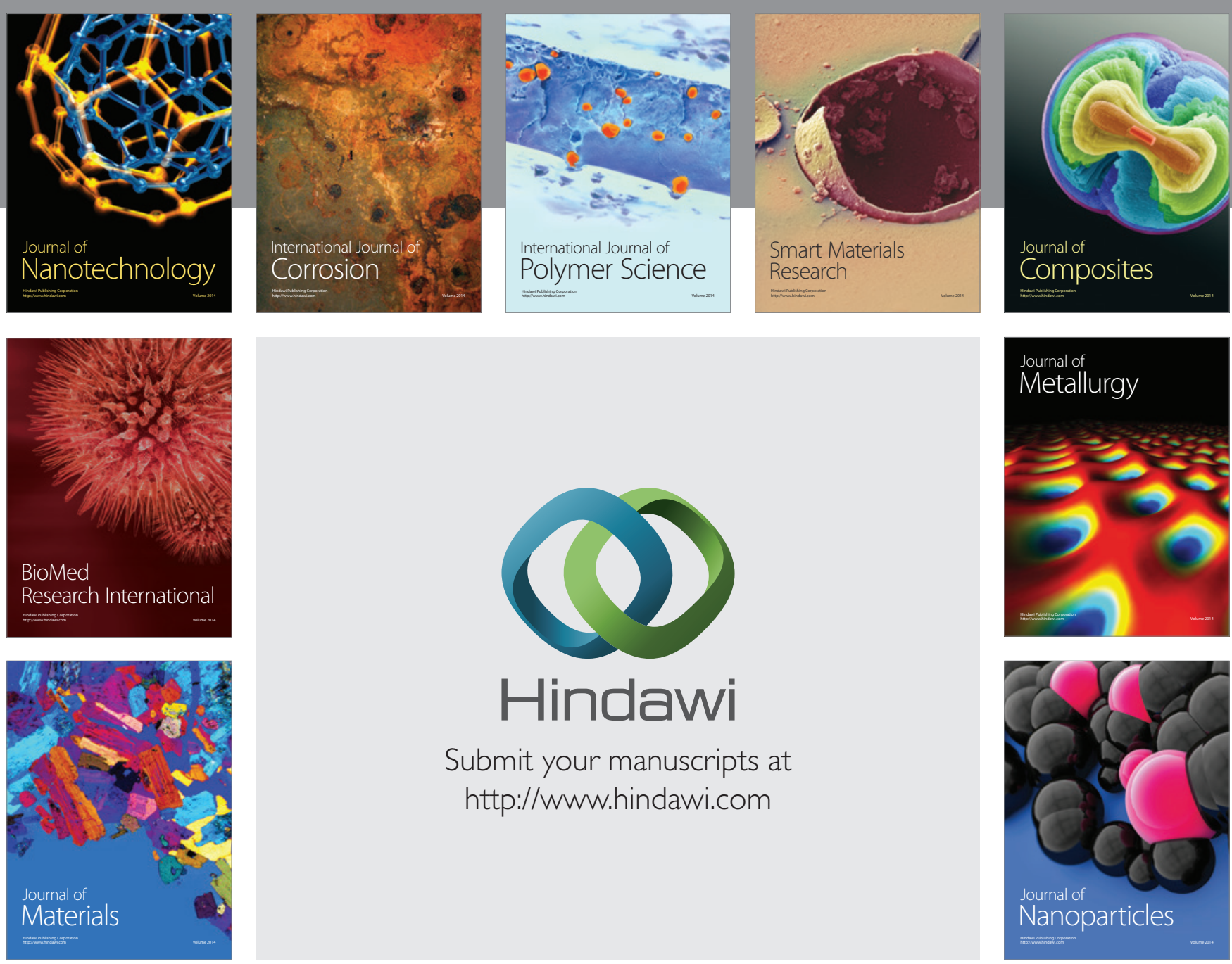

Submit your manuscripts at http://www.hindawi.com
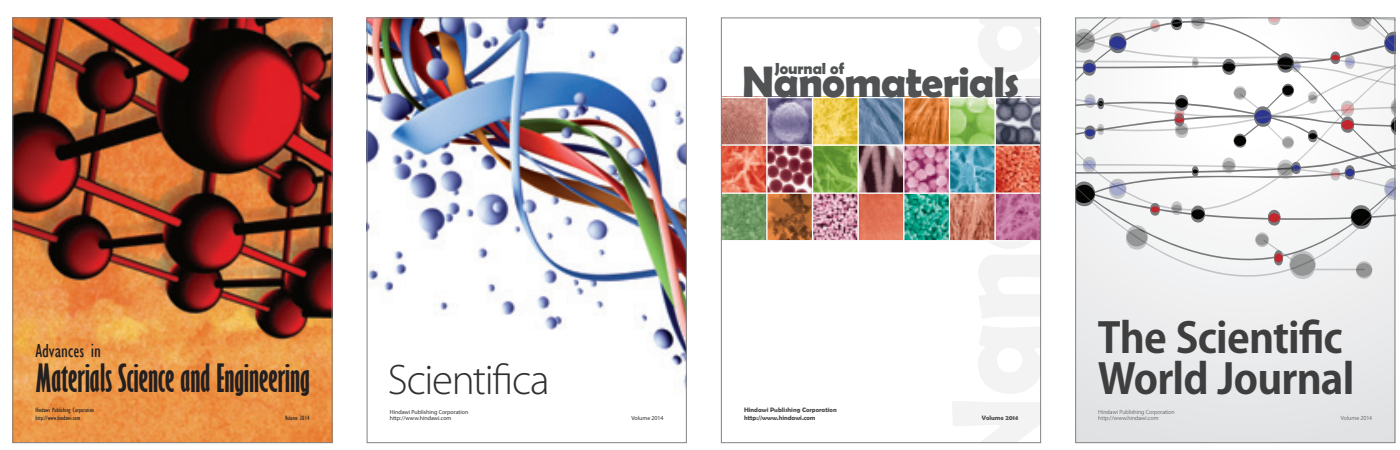

\section{The Scientific World Journal}
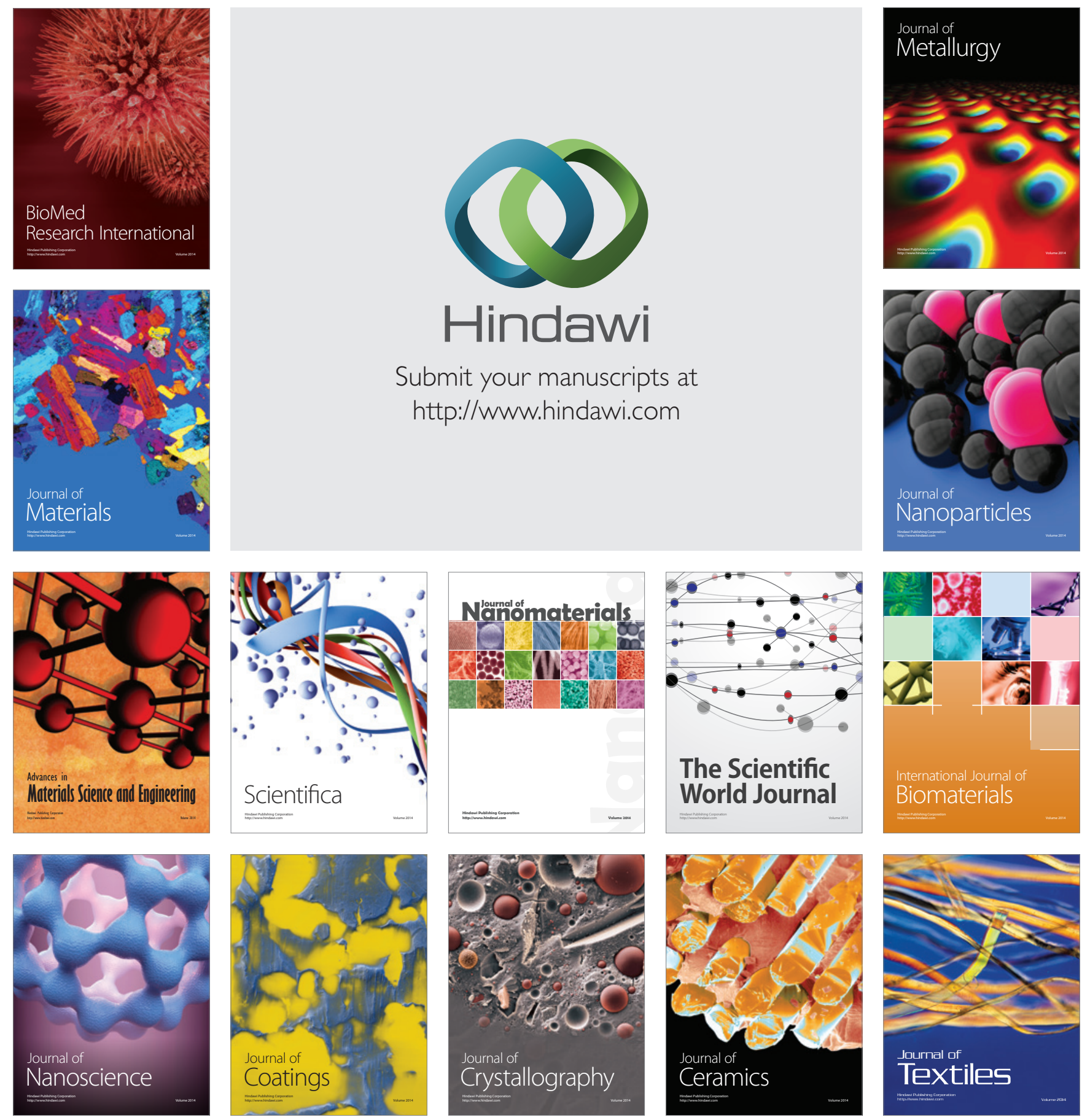